\title{
AVALIAÇÃO DAS PREFERÊNCIAS ECOLÓGICAS DE Clidemia urceolata DC. EM ECOSSISTEMAS PERTURBADO ${ }^{1}$
}

\author{
Cristiana do Couto Miranda ${ }^{2}$, Wanderson Henrique do Couto², Ricardo Valcarcel ${ }^{3}$, André Fellipe Nunes \\ de Freitas ${ }^{3}$ e Márcio Rocha Francelino ${ }^{4}$
}

\begin{abstract}
RESUMO - As identificações de hábitats preferenciais de espécies que colonizam espontaneamente ambientes perturbados podem constituir elementos de aperfeiçoamento de técnicas de restauração ecológica. Nesse contexto, a Clidemia urceolata DC destaca-se por colonizar esses ambientes e apresentar ampla distribuição na bacia do rio Paraíba do Sul. Este estudo objetivou avaliar as preferências ecológicas de C. urceolata na bacia hidrográfica

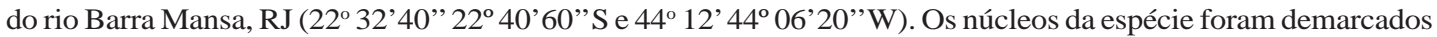
e classificados segundo os seguintes fatores ambientais: feição do terreno, posição relativa na topossequência, face de exposição, declividade e altitude. Foram amostrados 26 núcleos, totalizando 0,005 ha em 6.839 ha da área total. A distribuição da espécie foi mais frequente nos seguintes ambientes: a) terços médio e inferior da topossequência; b) feição côncava do terreno; c) face de exposições sudeste, sul e sudoeste; d) declividade de 8 a 45\%; e) altitude entre 432 e 525 m, sendo os últimos quatros fatores mais determinantes. A conjunção de todas essas informações espacializadas na bacia do rio Barra Mansa indica que $30 \%$ da área apresenta condições mais favoráveis para o estabelecimento da C. urceolata, o que pode demonstrar um potencial de restauração ambiental.
\end{abstract}

Palavras-chave: Áreas perturbadas, Espécies rústicas e Restauração ecológica.

\section{EVALUATION OF ECOLOGICAL PREFERENCES OF Clidemia urceolata DC. ON DISTURBED ECOSYSTEMS}

\begin{abstract}
The identification of preferential habitats of species which spontaneously colonize disturbed areas can constitute elements to improve ecological restoration techniques. Therefore, Clidemia urceolata DC stands out for colonizing those environments and presenting wide distribution in the watershed of Paraíba do Sul River. The objective of this study was to evaluate ecological preferences of $C$. urceolata in the watershed

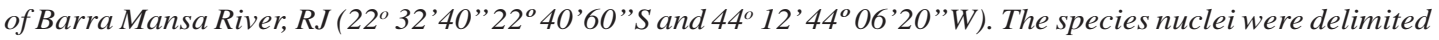
and classified according to the following environmental factors: terrain feature, relative position on toposequence, exposition face, slope and altitude. It was sampled 26 nuclei, totalizing 0.005 ha from 6.839 ha of total area. Species distribution was more frequent on the following conditions: a) medium and inferior thirds of the toposequence. $b$ ) concave face of the terrains. c) southeastern, southern and southwestern exposure faces. d) slope between 8 and 45\%. e) altitudes between 432 and $525 \mathrm{~m}$, being the four last factors the most determinant. The conjunction of this information ploted for the watershed of Barra Mansa River indicate that $30 \%$ of area present more favorable conditions for the establishment of C. urceolata, what can demonstrate an environmental restoration potential.
\end{abstract}

Keywords: Disturbed areas, Rustic species and Ecological restoration.

\footnotetext{
${ }^{1}$ Recebido em 18.11.2009 e aceito para publicação em 02.05.2011.

${ }^{2}$ Programa de Pós-Graduação em Ciências Ambientais e Florestais pela Universidade Federal Rural do Rio de Janeiro, UFRRJ, Brasil.E-mail: <coutomiranda@yahoo.com.br>e <whcouto@yahoo.com.br>.

${ }^{3}$ Departamento de Ciências Ambientais, Universidade Federal Rural do Rio de Janeiro, UFRRJ, Brasil. E-mail: <ricval@ufrrj.br> e<afnfreitas@gmail.com>.

${ }^{4}$ Universidade Federal Rural do Rio de Janeiro, UFRRJ, Brasil. E-mail: <marciorocha@ufrrj.br>..
} 


\section{INTRODUÇÃO}

A supressão da vegetação no passado recente, em especial da Mata Atlântica, e o uso inadequado dos solos têm gerado ecossistemas perturbados e tendência inercial à degradação, ou seja, empobrecimento paulatino dos ecossistemas mesmo com taxas de uso mínimo. No entanto, esses ecossistemas ainda mantêm meios de regeneração biótica (CARVALHO, 2000), ou resiliência mínima, capaz de promover a sua autoregeneração (CARPANEZZI, 2005).

Na bacia do rio Paraíba do Sul, os ecossistemas perturbados são oriundos dos ciclos econômicos realizados na região, em especial a cafeicultura e pecuária leiteira e de corte, que substituíram as florestas nativas. A inobservância de critérios conservacionistas levou à perda do potencial produtivo dos solos, que atualmente têm capacidade de suporte para sustentar vegetação rala e frágil. As extensas áreas em processo de degradação, variedades de processos erosivos, perda da qualidade da água e baixa produtividade agrícola representam evidências da magnitude da perturbação e acarretam perdas de serviços ambientais, como qualidade e disponibilidade hídricas e oscilações térmicas diárias abruptas. Esses processos prejudicam o desenvolvimento regional, podendo ser quantificados economicamente (COSTANZA et al., 1997).

Os ecossistemas perturbados constituem a principal paisagem da região do terço médio da bacia do rio Paraíba do Sul, onde há pequenos fragmentos florestais isolados entre pastagens abandonadas e níveis diferenciados de processos erosivos (TOLEDO; PEREIRA, 2004). Nas regiões de relevo acidentado, os problemas de erosão das encostas são frequentes, como na bacia do rio Barra Mansa, localizada na vertente direita, onde há maior incidência dos processos erosivos (CEIVAP, 2002).

Para reverter o atual quadro de degradação, faz-se necessário empregar modelos alternativos de recuperação nos ambientes perturbados, pois as comunidades encontram-se descapitalizadas e sem meios para investir. Assim, um projeto de restauração pode-se iniciar pelo levantamento dos serviços ambientais oferecidos pelos ecossistemas degradados ou alterados. Segundo Chazdon (2008), níveis originais desses serviços podem ser restabelecidos com o processo de recuperação.

A restauração de áreas onde ainda há solos com traços de matéria orgânica, mosaicos de pequenos fragmentos florestais e vegetação rala com predomínio de pastagens abandonadas requer estratégias especificas (VALCARCEL; SILVA, 1997). Segundo esses autores, tais estratégias demandam o conhecimento das espécies invasoras espontâneas da região que suportam as adversidades locais, como ataque de insetos, estresses hídrico e térmico, fogo e pastoreio extensivo.

Algumas espécies exóticas têm sido utilizadas como iniciais no estabelecimento de processos sucessionais, principalmente pela sua rusticidade (CORTINES; VALCARCEL, 2009; ROPPA, 2009). No entanto, o grande desafio da restauração como ciência é ampliar o conjunto de espécies nativas rústicas o suficiente para colonizar, estabelecer populações viáveis e desenvolver propriedades emergentes, de modo a se tornarem espécies facilitadoras da sucessão ecológica, constituindo modelos naturais de restauração de ecossistemas perturbados.

O conhecimento de diferentes estratégias de estabelecimento adotadas pelas espécies vegetais pioneiras viabiliza projetos sustentáveis de restauração florestal. Nesse contexto, foi selecionada para este estudo a espécie Clidemia urceolata DC. (Melastomataceae), que coloniza naturalmente pastagens abandonadas na bacia do rio Paraíba do Sul (MENEZES, 2008). Essa espécie pode ser indicadora de atributos ambientais importantes no processo de restauração ambiental. Possui hábito arbustivo, com altura variando entre 0,5 e 2 m (GOLDENBERG et al., 2005). Sua distribuição agregada forma núcleos de tamanhos variados, em que podem ser observadas outras espécies de diferentes hábitos, entre as quais se destaca a Cecropia pachystachya Trécul. Outras espécies pioneiras da mesma família são frequentes nos processos de regeneração natural dos ecossistemas florestais alterados (ARAÚJO et al., 2001; TRÊS et al., 2007; BRAGA et al., 2008), tendo importante função na reversão de tendência de degradação dos ecossistemas, pois são as primeiras a ativar mecanismos de resiliência. Por essas importantes habilidades, conhecer seus hábitats preferenciais é fundamental para aperfeiçoar suas estratégias de colonização espontânea. Dessa forma, colabora no processo de restauração florestal.

Este estudo objetivou avaliar as preferências ecológicas de Clidemia urceolata em ambientes perturbados na bacia hidrográfica do rio Barra Mansa, no médio Paraíba do Sul, tendo como objetivos específicos: 1) avaliar se as variações dos fatores ambientais influenciam na distribuição da C. urceolata; 
2) determinar os fatores ambientais que mais contribuem para explicar a distribuição da espécie; e 3) definir a área da bacia hidrográfica que melhor favoreça o estabelecimento dessa espécie.

\section{MATERIAL E MÉTODOS}

\section{1. Área de estudo}

A área de estudo compreende os trechos médio e inferior da bacia hidrográfica do rio Barra Mansa (6.839ha), localizada no Município de Barra Mansa, Estado do Rio de Janeiro, entre as coordenadas $22^{\circ} 32^{\prime} 40^{\prime \prime} \mathrm{e}$

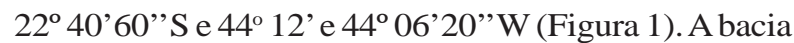
do rio Barra Mansa encontra-se no domínio do bioma Mata Atlântica (RADAMBRASIL, 1983), apresentando vegetação florestal secundária fragmentada e reduzida a menos de 3\% da área do município (COPPE-UFRJ, 2000). As pastagens de baixa produtividade e altos níveis de degradação ocupam mais de $80 \%$ da bacia, com cicatrizes de processos erosivos em todas as regiões, notadamente no seu trecho médio, onde o relevo é mais movimentado.

O clima é do tipo Aw pela classificação de Köppen, apresentando médias anuais de precipitação e temperatura de $1.300 \mathrm{~mm}$ e $20,9^{\circ} \mathrm{C}$, respectivamente (dados da Estação Piraí referentes a 1962 - 1990) (INMET, 2009). Na região da bacia hidrográfica do rio Barra Mansa, os argissolos são predominantes (COPPE-UFRJ, 2000), especialmente onde o relevo é acidentado e nas áreas com variação altitudinal entre 380 e 664 m.

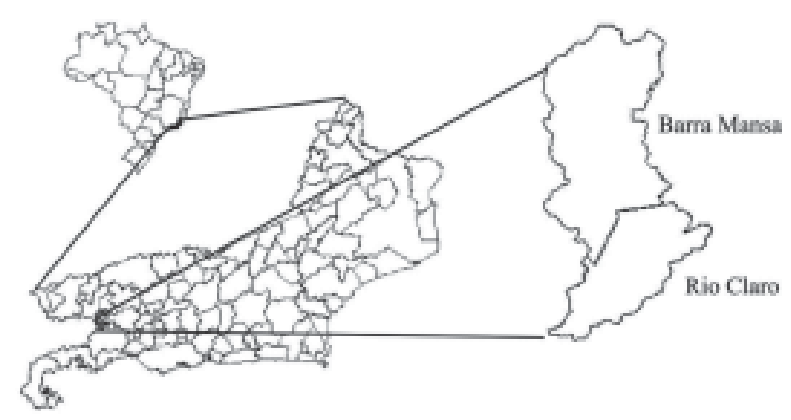

Figura 1 - Localização da bacia do rio Barra Mansa, RJ, com a delimitação do trecho superior pertencente ao Município de Rio Claro e os trechos médio e inferior do Município de Barra Mansa.

Figure 1 - Location of the watershed of Barra Mansa River, $R J$, with delimitation of the superior part belonging to the district of Rio Claro and the medium and inferior part to the Municipal district of Barra Mansa.

\subsection{Amostragem}

Para avaliar as preferências ecológicas de $C$. urceolata em ecossistemas perturbados, foi feito o censo de todos os núcleos da espécie distribuídos no trecho médio e inferior da bacia do rio Barra Mansa, nas áreas onde havia acesso. Os núcleos foram georreferenciados e classificados de acordo com os seguintes fatores ambientais: feição do terreno, posição relativa na toposequência, face de exposição, declividade e altitude, cujas metodologias se encontram descritas na literatura corrente (ZAÚ, 1994; BONAN, 2002; CARDOSO; SCHIAVINI, 2002; MARTINS et al., 2003; MARQUES et al., 2004).

\subsection{Zoneamento dos núcleos de Clidemia urceolata}

Os núcleos foram determinados com o auxílio de GPS Garmim Etrex Venture, base cartográfica planialtimétrica de Volta Redonda, na escala de 1:50.000 (disponível no site do IBGE), imagens do Google Earth e programa ArcGIS 9.2.

A carta planialtimétrica foi baixada do portal do IBGE e as curvas de nível, cotadas por meio do programa ArcInfo. Os dados foram gerados no formato shapefile (arquivo vetorial utilizado no pacote de programas ArcGis), no ArcMap, com projeção UTM (Universal Transverse Mercator). Os mapas gerados estão na escala 1:50.000.

As imagens foram georreferenciadas no programa ArcMap e sobrepostas à base cartográfica. Posteriormente, os pontos coletados com GPS foram georreferenciados sobre a base cartográfica, segundo o procedimento descrito por Figueiredo et al. (2002). Os núcleos de $C$. urceolata foram delimitados por meio da ferramenta sketch tool do ArcMap.

\subsection{Determinação dos fatores ambientais}

As áreas nucleadas foram classificadas de acordo com os padrões de variação determinados para os seguintes fatores ambientais: a) feição do terreno: côncava, plana, convexa; b) posição relativa na topossequência: terço inferior, médio e superior (MARTINS et al., 2003); c) face de exposição: norte, nordeste, leste, sudeste, sul, sudoeste, oeste e noroeste (BONAN, 2002; MARQUES et al., 2004); d) classes de declividade (\%): plana (0-3), suave-ondulado (3-8), ondulado (8-20), forte-ondulado (20-45), montanhoso (45-75) e escarpado (> 75) (EMBRAPA,

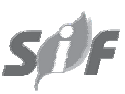

Revista Árvore, Viçosa-MG, v.35, n.5, p.1135-1144, 2011 
2006); e e) classes de altitude: 384-431, 432-478, 479525, 526-572, 573-619 e 620-665, definidas com base na divisão igualitária dos limites máximos e mínimos de altitude da área de estudo. A partir da carta planialtimétrica, gerou-se o modelo digital de elevação (MDE), do qual foram derivados os mapas de face de exposição, declividade e feição do terreno.

As preferências ecológicas da espécie foram obtidas a partir da análise de frequência de ocorrência dos núcleos de C. urceolata. Diferenças entre essas frequências foram analisadas através do teste de QuiQuadrado (ZAR, 1999). Para identificar os fatores ambientais que explicam com maior expressão a distribuição da espécie, foi realizada a análise de componentes principais (PCA) (LEGENDRE; LEGENDRE, 1998).

\subsection{Confecção de mapas de preferência ecológicas da C. urceolata}

Para definição de áreas de preferência da espécie foram gerados mapas temáticos de altitude, declividade, concavidade do terreno e faces de exposição, através da ferramenta single output map algebra do programa ArcGIS 9.2. Cada mapa é constituído de áreas inaptas (ausentes de atributos preferenciais pela C. urceolata) e áreas preferenciais (contendo as classes dos fatores ambientais mais frequentemente colonizadas pela espécie). Ao final, os quatro mapas parciais foram somados, gerando um mapa geral de gradientes de preferência ecológica, composto por cinco classes de preferência: ótima, boa, regular, ruim e inapta, que correspondem às áreas contendo classes preferenciais de quatro, três, dois, um e nenhum dos fatores ambientais.

\section{RESULTADOS}

Foram amostrados 26 núcleos de Clidemia urceolata, que correspondem a 0,005 ha dos 6.839 ha do trecho médio e inferior da bacia do rio Barra Mansa. A distribuição desses núcleos diferiu significativamente entre as classes da feição do terreno $\left(\chi^{2}=19,85\right.$, $\alpha=1 \%$, gl = 4; Figura 2A), topossequência $\left(\chi^{2}=311,11\right.$, $\alpha=1 \%$, gl = 5; Figura 2B), face de exposição $\left(\chi^{2}=32,46\right.$, $\alpha=1 \%$, gl = 7; Figura 2C), declividade $\left(\chi^{2}=21,56\right.$, $\alpha=1 \%$, gl $=5$; Figura 2D) e altitude $\left(\chi^{2}=36,44\right.$, $\alpha=1 \%$, gl = 5; e Figura 2E). A maior frequência dos núcleos foi observada ocupando classes específicas desses fatores ambientais: 57,7\% nas áreas de feição côncava do terreno, 65,4\% no terço médio e inferior da topossequência, 88,5\% nas áreas com face de exposição sudeste, sul e sudoeste, $73 \%$ nas áreas com declividade entre 8 e $45 \%$ e $88,5 \%$ nas áreas com altitude entre 432 e $525 \mathrm{~m}$.

Os resultados evidenciaram que a bacia hidrográfica possui declividade que varia de 0 a $61 \%$ e altitude de 384 a 664 m, ou seja, possui áreas desde planas a montanhosas e uma variação altitudinal de $280 \mathrm{~m}$. No entanto, entre essas variações os núcleos da espécie em estudo concentraram-se em faixas específicas, como descrito anteriormente.

A análise de componentes principais indicou que a maior parte da variação do componente 1 (primeiro eixo) foi explicada pela declividade $(56,5 \%)$, seguidos pela feição do terreno (53,3\%) e face de exposição (53,3\%), enquanto o componente 2 (segundo eixo) foi mais bem explicado pela altitude (71,9\%) (Figura 3).

O mapa de preferências ecológicas da C. urceolata para a bacia do rio Barra Mansa, gerado com base nas faixas dos fatores ambientais com maior frequência da espécie (1: feição côncava do terreno; 2: face de exposição sudeste, sul e sudoeste; 3: declividade de 8 a 45\%; e 4: altitude entre 432 e 525 m) demonstrou que aproximadamente $30 \%$ da área dessa bacia hidrográfica se encontrava nas classes boa e ótima para o desenvolvimento da C. urceolata, ou seja, com presença das faixas preferenciais, pela espécie, de três e quatro fatores ambientais, respectivamente (Figura 4).

\section{DISCUSSÃO}

A maior porcentagem dos núcleos de C. urceolata nas feições côncavas do terreno pode ser justificada pela presença de abrigos para os agentes climáticos, como as barreiras orográficas. Há também as combinações dos efeitos decorrentes da oferta diferenciada de recursos ambientais, conferidas pelas zonas de convergência do fluxo de água. Feições côncavas acumulam mais água, sedimentos, matéria orgânica e nutrientes (CARDOSO; SCHIAVIN, 2002), que facilitam o estabelecimento de plantas. Esses recursos, por sua vez, conferem certo grau de resiliência aos ecossistemas perturbados. Isso pode ser corroborado pelos estudos de Zaú (1994), que verificou que na presença dos distúrbios antrópicos as áreas florestadas possuíam tendência a persistir somente em zonas de convergência de fluxos de água. No movimento de água para as zonas côncavas, a matéria orgânica e sementes podem ser 

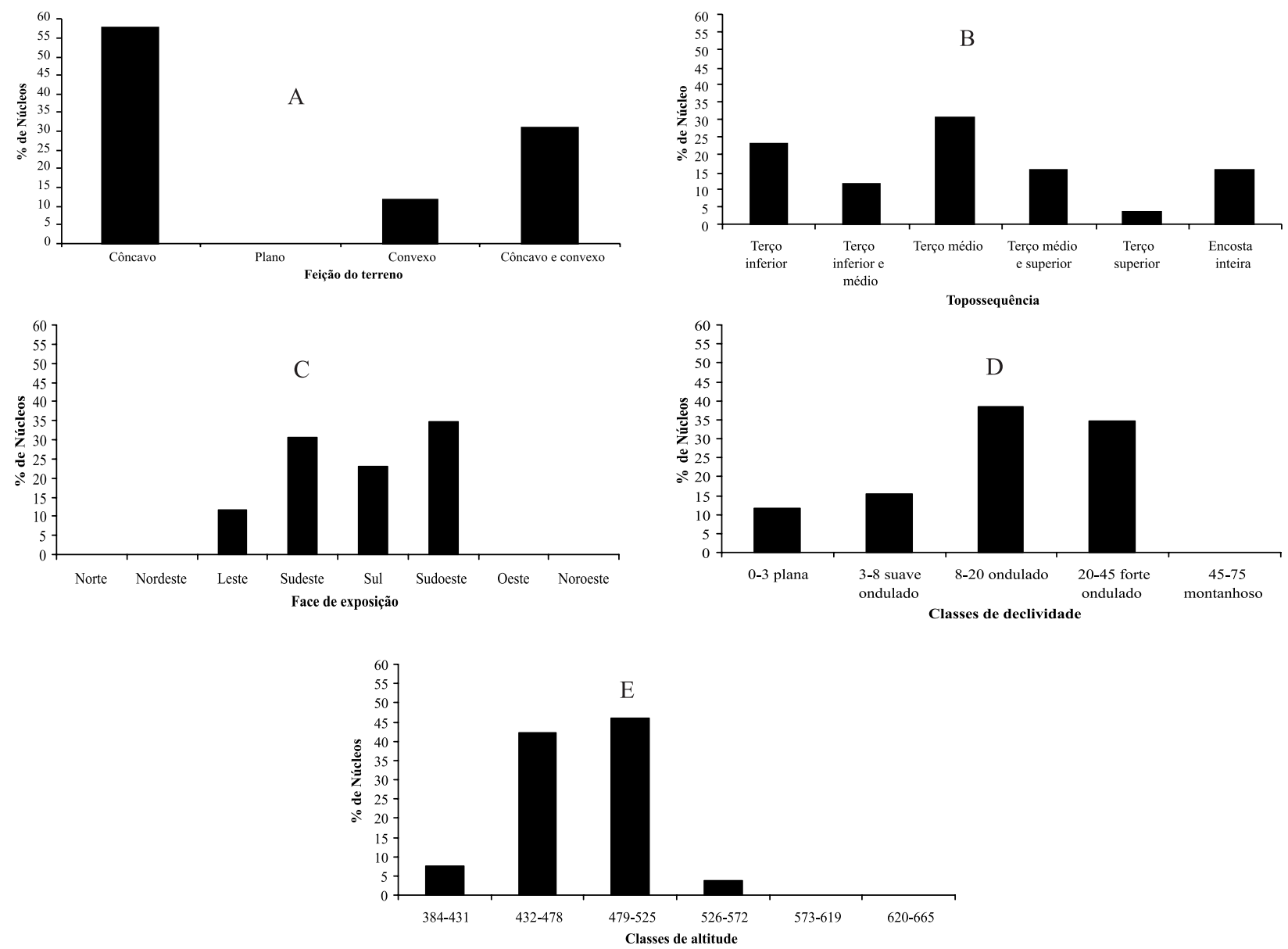

Figura 2 - Variação da porcentagem de núcleos de Clidemia urceolata em relação à feição do terreno (A), topossequência (B), face de exposição (C), declividade (D) e altitude (E) na bacia do rio Barra Mansa, RJ.

Figure 2 - Variation of the percentage of Clidemia urceolata nuclei in relation to the terrain feature (A), topossequence $(B)$, exposure face (C), slope (D) and altitude (E) in the watershed of Barra Mansa River, $R J$.

carreadas, acumulando-se nas depressões (CARDOSO; SCHIAVIN, 2002). Em ecossistemas pouco antropizados, a retenção de água e disponibilidade de nutrientes são determinantes para definir o tipo de vegetação (ROSSI et al., 2005). Nos ecossistemas perturbados, esses recursos aumentam a resiliência e criam propriedades emergentes, que condicionam o resgate da biodiversidade.

Para o fator topossequência, os recursos ambientais estão relacionados aos seus padrões de variação, pois a hidrologia de vertentes influencia os tipos de solos e, consequentemente, a distribuição das espécies vegetais. Segundo a teoria de Milne (1936), nas áreas do terço inferior das encostas o escoamento superficial é baixo e a infiltração alta, o que favorece maior oferta hídrica nesse ambiente. Esse fato é potencializado pela umidade e sedimentos provenientes dos terços médio e superior, que aumentam a profundidade e fertilidade dos solos no terço inferior das encostas. De acordo com Martins et al. (2003), solos de baixada são mais arenosos, férteis e menos ácidos, possuindo distribuição de espécies peculiares em ambientes de Mata Atlântica.

Em áreas perturbadas com relevos acidentados, o terço médio das encostas é a região de maior dinâmica de processos erosivos, em que as suas cicatrizes são as principais áreas colonizadas pela C. urceolata, o

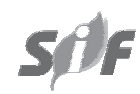

Revista Árvore, Viçosa-MG, v.35, n.5, p.1135-1144, 2011 


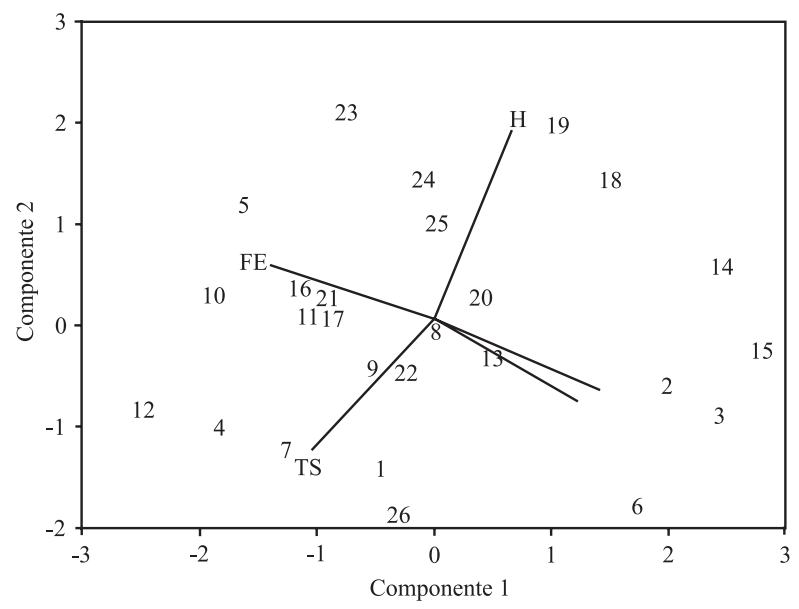

Figura 3 - Diagrama de ordenação obtido pela análise dos componentes principais (PCA), dos 26 núcleos de Clidemia urceolata em relação à feição do terreno (FT), topossequência (TS), face de exposição (FE), declividade (D) e altitude (H) na bacia do rio Barra Mansa, RJ.

Figure 3 - Ordination diagram obtained by main components analysis (MCA) of 26 nuclei of Clidemia urceolata in relation to terrain feature ( $F T$ ), toposequence (TS), exposure face (FE), slope (D) and altitude $(H)$ in the watershed of Barra Mansa River, RJ.

que possivelmente é atribuído à maior oferta de umidade e nutrientes. Nesse contexto, destaca-se a relação entre os fatores feição do terreno e topossequência, que podem determinar a disponibilidade de recursos no ambiente, favorecendo o processo de colonização inicial de áreas perturbadas, além de possibilitar a evolução sucessional desse ecossistema.

As preferências ecológicas da C. urceolata por classes específicas do fator face de exposição, evidenciada pela maior porcentagem da espécie nas vertentes sudoeste, sul e sudeste $(88,5 \%)$, podem ser atribuídas às diferentes condições ambientais ofertadas pela influência das vertentes. Esse fator é um aspecto importante na determinação de áreas com maior oferta de recursos ambientais e resiliência (MARQUES et al., 2004). Em parte, isso se deve ao fato de as vertentes afetarem as perdas hídricas por transpiração e evaporação, devido à influencia sobre a quantidade de radiação solar recebida (LIMA, 1986).

De acordo com Pereira et al. (2002), no Hemisfério Sul a trajetória leste-oeste do Sol sofre declinação para o norte. Esse fato faz os raios solares tenderem a interceptar

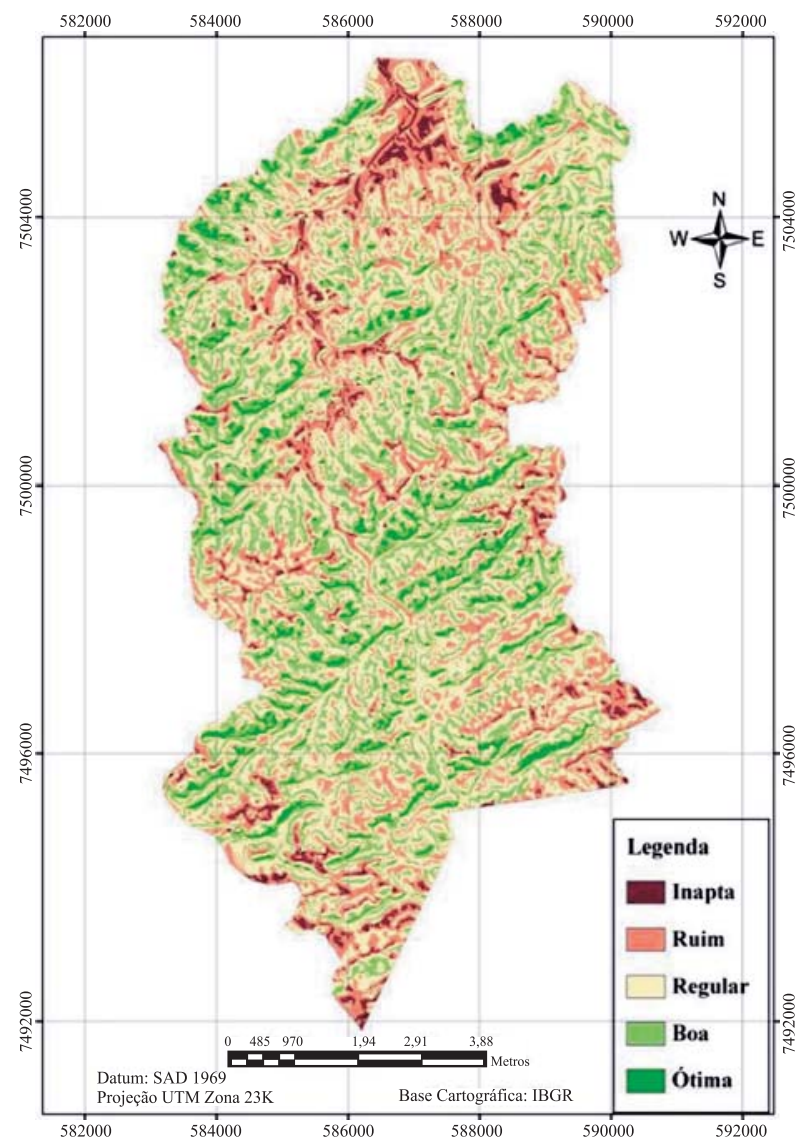

Figura 4 - Áreas com preferências ecológicas para o desenvolvimento espontâneo da Clidemia urceolata na bacia do rio Barra Mansa, RJ.

Figure 4-Areas with ecological preferences for spontaneous development of Clidemia urceolata in the watershed of Barra Mansa River, RJ.

as superfícies voltadas para o norte e tangenciarem as voltadas para o sul (FERREIRA et al., 2005). Segundo esse mesmo autor, tal efeito será mais pronunciado quanto mais movimentado for o relevo da área. O ângulo de incidência dos raios solares promove alterações na quantidade de calor transmitida (BONAN, 2002). Assim, as superfícies voltadas para o norte recebem mais energia que as voltadas para o sul, tendo maior evapotranspiração potencial e menor umidade. Dessa forma, as vertentes leste e sul possuem menor influência desses fatores e, consequentemente, maior umidade, favorecendo o estabelecimento e desenvolvimento espontâneo de fragmentos florestais (MIRANDA; OLIVEIRA, 1983; OLIVEIRA et al., 1995). 
No Município do Rio de Janeiro, as vertentes voltadas para leste e sul são mais úmidas, com vegetação ombrófila, enquanto as vertentes norte e nordeste apresentam vegetação com caducifolia (LIMA, 1986; MARQUES et al., 2004). A diferença paisagística e florística entre as vertentes sugerem que a face de exposição contribui, de forma distinta, na capacidade de o ecossistema reter água e, como resultado, na formação e manutenção de fragmentos florestais.

Outro atributo estritamente relacionado à face de exposição são os ventos úmidos. De acordo com alguns estudos, esses ventos proporcionam maior interceptação de umidade nas encostas a barlavento em relação às encostas a sotavento (MARQUES et al., 2004; BARBOZA, 2007). No litoral do Estado do Rio de Janeiro, as encostas voltadas para a vertente sudoeste, ou seja, perpendicular à entrada de ventos úmidos, interceptam mais umidade (BARBOZA, 2007). Isso propicia variações no ambiente, deixando as encostas a barlavento, no caso a sudoeste, mais úmidas e propícias à presença de fragmentos florestais (MIRANDA; OLIVEIRA, 1983; OLIVEIRA et al., 1995; MARQUES et al., 2004).

Essas evidências demonstram que a face de exposição possui grande influência sobre a umidade, através da ação dos raios solares e dos ventos. Neste estudo, as faces sudoeste, sul e sudeste podem ser as vertentes com maior oferta de recursos ambientais, em especial a maior oferta hídrica, que por sua vez pode estar favorecendo a colonização e formação dos núcleos de C. urceolata.

Conjuntamente à face de exposição, a declividade interfere de forma substancial na oferta hídrica, tendo relação com vários processos hidrológicos, como infiltração e escoamento superficial (LIMA, 1986), que em conjunto com outros fatores resulta em gradientes de umidade no solo entre o topo e a base da vertente (GANDOLFI, 2000; CARDOSO; SCHIAVINI, 2002). Elevadas declividades aumentam a velocidade de escoamento superficial, o que reduz o período de infiltração. Nesse contexto, a atuação da ação do intemperismo químico causado pela água sobre as rochas é menor (LEPSCH, 2002). A lenta formação dos solos acrescida do elevado processo erosivo das encostas declivosas resulta em solos pouco desenvolvidos, que podem dificultar o estabelecimento de espécies vegetais em decorrência da dificuldade de enraizamento, baixa disponibilidade hídrica e de nutrientes. Essa carência de recursos pode estar dificultando o estabelecimento da C. urceolata em áreas muito declivosas (superiores a 45\%). Outros estudos também identificaram a declividade como fator limitante à ocorrência de diversas espécies florestais (CARDOSO; SCHIAVINI, 2002; MORENO, 2001).

A baixa frequência dos núcleos de $C$. urceolata nas áreas planas e suave-onduladas (0-8\%) pode estar relacionada à pressão e frequência de uso, uma vez que essas áreas possuem maior facilidade de acesso. No entanto, a ausência dos núcleos nas áreas com maior altitude (> $573 \mathrm{~m}$ ) pode ser atribuída à presença de fragmentos florestais, que impedem a entrada da C. urceolata, por criar condições microclimáticas desfavoráveis ao estabelecimento da espécie, que necessita de locais abertos para colonizar.

Outros limitantes da colonização da C. urceolata podem ser as condições macroclimáticas determinadas pela altitude. A variação altitudinal tem relação direta com a mudança da temperatura e precipitação (LIMA, 1986; BONAN, 2002). De acordo com Wever e Clements (1980), com o aumento da altitude há redução da temperatura, o que resulta em restrição de hábitat para algumas espécies. Isso pode ser comprovado pelo estudo de Blum e Roderjan (2007), que, avaliando um gradiente da Floresta Ombrófila Densa na Serra da Prata no Paraná, constataram espécies que possuem preferência por faixa altitudinal, sendo limitada a essa área. Gomes et al. (2005), analisando a florística ao longo de um gradiente altitudinal, determinaram variação contínua na composição de espécies ao longo de 125 m de diferença de elevação. Isso demonstra que determinadas espécies são restritas a uma faixa de altitude; a C. urceolata pode ser uma dessas espécies. No entanto, são necessários estudos mais minuciosos que possam avaliar, com mais precisão, esse comportamento.

De forma geral, foi possível constatar que determinadas classes dos fatores ambientais analisados são prioritárias à colonização da C. urceolata. Segundo Cardoso e Schiavini (2002), o relevo, a luminosidade, a distribuição de nutrientes e a saturação de água do solo atuam sobre a distribuição das espécies, conferindo-lhes a oportunidade de predomínio. Esses diferentes gradientes determinados pela variação dos fatores ambientais podem estar restringindo áreas com diferentes graus de prioridades de ocupação da C. urceolata. No entanto, alguns desses fatores são mais relevantes nesse processo.

Revista Árvore, Viçosa-MG, v.35, n.5, p.1135-1144, 2011 
Os resultados da análise de componentes principais indicam que os fatores ambientais analisados que mais contribuíram para explicar a distribuição dos núcleos de C. urceolata foram altitude, declividade, feição do terreno e face de exposição. O mapa de preferências ecológicas da C. urceolata gerado com base nesses fatores (Figura 4) indica que aproximadamente $30 \%$ da área da bacia do rio Barra Mansa encontra-se nas classes boa e ótima para o desenvolvimento da C. urceolata, ou seja, que apresenta condições mais favoráveis ao estabelecimento dessa espécie, pois possui predominância das classes prioritárias dos fatores ambientais avaliados. Essas informações retratam o potencial de início da restauração espontânea da bacia, considerando que a C. urceolata exerce o papel de colonizadora inicial e, segundo Miranda et al. (dados não publicados), contribui com matéria orgânica, melhorando as condições de fertilidade e cobertura do solo. Dessa forma, essa espécie pode estar permitindo o avanço da sucessão florestal de acordo com o modelo de facilitação descrito por Connell e Slatyer (1977). Nesse modelo, as espécies pioneiras invadem lentamente um sítio disponível à colonização e facilitam o estabelecimento de outras, pois agem como atrativo/ abrigo para os dispersores, melhoram as condições de fertilidade e cobertura do solo e fornecem condições ambientais adequadas à germinação (UHL, 1987). No entanto, outros estudos são necessários, a fim de validar o modelo de facilitação da C. urceolata.

\section{CONCLUSÕES}

Os núcleos de Clidemia urceolata mostraramse mais frequentes nas áreas que correspondem à feição côncava do terreno, terços médio e inferior da topossequência, face de exposição sudeste, sul e sudoeste, declividade de 8 a $45 \%$ e altitude entre 432 e $525 \mathrm{~m}$, evidenciando que há preferências ecológicas para a colonização e estabelecimento da espécie.

Entre os fatores avaliados, a altitude, declividade, feição do terreno e face de exposição foram mais determinantes na distribuição dos núcleos.

Trinta por cento da bacia do rio Barra Mansa apresenta condições mais favoráveis ao estabelecimento da C. urceolata, o que pode representar um potencial de início da restauração ecológica desses ecossistemas perturbados.

\section{AGRADECIMENTOS}

À CAPES, pela bolsa de doutorado à primeira autora; e à Prefeitura Municipal de Barra Mansa, pelo apoio.

\section{REFERÊNCIAS}

ARAUJO, M. M. et al. Densidade e composição florística do banco de sementes do solo de florestas sucessionais na região do Baixo Rio Guamá, Amazônia Oriental. Scientia Florestalis, n. 59, p.115-130, 2001.

BARBOZA, R. S. Caracterização das bacias aéreas e avaliação da chuva oculta nos contrafortes da serra do Mar - RJ. 2007. 56f. Dissertação (Mestrado em Ciências Ambientias e Florestais) - Universidade Federal do Rural do Rio de Janeiro, Seropédica, RJ. 2007.

BLUM, C. T.; RODERJAN, C. V. Espécies Indicadoras em um Gradiente da Floresta Ombrófila Densa na Serra da Prata, Paraná, Brasil. Revista Brasileira de Biociências, v.5, n.2, p.873-875, 2007.

BONAN, G. Ecological Climatology. New York: Cambridge University Press, 2002. 678p.

BRAGA, A. J. T. et al. Composição do banco de sementes de uma floresta semidecidual secundária considerando o seu potencial de uso para recuperação ambiental. Revista Árvore, v.32, n.6, p.1089-1098, 2008.

CARDOSO, E.; SCHIAVINI, I. Relação entre distribuição de espécies arbóreas e topografia em um gradiente florestal na Estação Ecológica do Panga (Uberlândia, MG). Revista Brasileira de Botânica, v.25, n.3, p.277-289, 2002.

CARPANEZZI, A. A. Fundamentos para a reabilitação de ecossistemas floretais. In: GALVÃO, A. P. M.; SILVA, V. P. (Ed.). Restauração florestal: fundamentos e estudos de caso. Colombo: Embrapa Florestas, 2005. p.27-45.

CARVALHO, P. E. R. Técnicas de recuperação e manejo de áreas degradadas. In: GALVÃO, A. P. M. (Org.). Reflorestamento de propriedades rurais para fins produtivos e ambientais: um guia para ações municipais e regionais. Brasília: Embrapa, 2000. p.251-268. 
COMITÊ PARA INTEGRAÇÃO DA BACIA HIDROGRÁFICA DO RIO PARAÍBA DO SUL -

CEIVAP. Diagnóstico da situação atual dos recursos hídricos. In: Plano da bacia do Rio Paraíba do Sul.. Fundação Coppetec. UFRJ. Agência Nacional das Águas (ANA). 2002. 1200p. v.1-8. <http://www.ceivap.org.br/ planobacia.htm> Acesso em 10 de junho de 2008.

CHAZDON, R. L. Beyond deforestation: restoring forests and ecosystem services on degraded lands. Science, v.320, p.1458-1460, 2008.

CONNELL, J. H.; SLATYER, R. O. Mechanisms of succession in natural communities and their role in community stability and organization. The American Naturalist, v.111, n.982, p.1119-1144, 1977.

COPPE-UFRJ. Projeto preparatório para o gerenciamento dos recursos hídricos do Paraíba do Sul: Projeto-piloto de controle de erosão em Barra Mansa (RJ). Rio de Janeiro. 2000. 27p. <http:// www.ceivap.org.br $>$ Acesso em 14 de junho de 2005.

CORTINES, E.; VALCARCEL, R. Influence of pioneer-species combinations on restoration of disturbed ecosystems in the Atlantic Forest, Rio de Janeiro, Brazil. Revista Árvore, v.33, n.5, p.927-936, 2009.

COSTANZA, R. et al. The value of the world's ecosystem services and natural capital. Nature, v.387, n.15, p.253-260, 1997.

EMPRESA BRASILEIRA DE PESQUISA AGROPECUÁRIA - EMBRAPA. Sistema brasileiro de classificação de solos. 2.ed. Rio de Janeiro: Embrapa Solos, 2006. 306p.

FERREIRA, F. P. et al. Exposição solar e propriedades do solo em Santa Maria - RS. Revista Brasileira de Agrociência, v.11, n. 3, p.377-381, 2005.

FIGUEIREDO, A. O.T.; MADRUGA, P. R. A.; PEREIRA, R. S. Geoprocesamiento aplicado al analisis del uso de la tierra em el município de San Piedro de Ycuanadyyú, Paraguai. Ciência Florestal, v.12, n.2, p.177-185, 2002.
GANDOLFI, S. História natural de uma floresta estacional semidecidual no município de Campinas (SP, Brasil). 2000. 520f. Tese (Doutorado em Biologia Vegetal) - Universidade Estadual de Campinas, Campinas, 2000.

GOLDENBERG, R.; SOUZA, C. M. F.; DEQUECH, H. B. Clidemia, Óssea e Pleiochiton

(Melastomataceae) no estado do Paraná, Brasil.

Hoehnea, v.32, n.3, p.453-466, 2005.

GOMES, E. P. C.; FISCH, S. T. V.; MANTOVANI, W. Estrutura e composição do componente arbóreo na Reserva Ecológica do Trabiju, Pindamonhangaba, SP, Brasil. Acta Botânica Brasilica, v.19, n.3, p.451-464, 2005.

INSTITUTO NACIONAL DE METEOROLOGIA INMET. Normais climatológicas. Disponível em: <http://www.inmet.gov.br/html/ clima.php> Acesso em: 02 de março de 2009.

LEGENDRE, P.; LEGENDRE, L. Numerical Ecology. Amsterdam: Elsevier Science B.V., 1998. 853p.

LEPSCH, I. F. Formação e Conservação dos solos. São Paulo: Oficina de Textos, 2002.178p.

LIMA, W. P. Princípios de hidrologia florestal para o manejo de Bacias Hidrográficas. São Paulo: USP, 1986. 242p.

MARQUES, O. et al. Atributos ambientais definidores de presença de fragmentos florestais de Mata Atlântica em microbacias instáveis. EDUR.

Revista Universidade Rural Série Ciências da Vida, v.24, n. 2, p.145-150, 2004.

MARTINS, S. V. et al. Distribuição de espécies arbóreas em um gradiente topográfico de Floresta Estacional Semidescidual em Viçosa, MG.

Scientia Forestalis, n.64, p.172-181, 2003.

MENEZES, C. E. G. Integridade de paisagem, manejo e atributos do solo no Médio Vale do Paraíba do Sul, Pinheiral-RJ. 2008. 164f. Tese (Doutorado em Agronomia)-Universidade Federal Rural do Rio de Janeiro, Seropédica, 2008.

MILNE, G. Normal erosion as a factors in soil profile development. Nature, v.138, p.548-549, 1936.

Revista Árvore, Viçosa-MG, v.35, n.5, p.1135-1144, 2011 
MIRANDA, E. L. F.; OLIVEIRA, R. R. Orquídeas rupícolas do Morro do Pão de Açúcar, Rio de Janeiro. Atas da Sociedade de Botânica do Brasil, Seção RJ. v.1, n.18, p.99-105, 1983.

MORENO, M. I. C. Relação entre vegetação e solo em um gradiente florestal na Estação Ecológica do Panga, Uberlândia, MG. Revista Brasileira de Botânica, v.24, n.4, p.537-544, 2001.

OLIVEIRA, R. R. et al. Significado ecológico da orientação de encostas no maciço da Tijuca, Rio de Janeiro. Oecologia Brasiliensis, v.1, p.523-541, 1995.

PEREIRA, R. A.; ANGELOCCI, L. R.; SENTELHAS, P. C. Agrometereologia. Guaibá:

Agropecuária, 2002. 478p.

RADAMBRASIL. Levantamento dos recursos Naturais: folha SF. 23/24 Rio de Janeiro/Vitória: Ministério de Minas e Energia, Rio de Janeiro: 1983. v.32. 780p.

ROSSI, M. et al. Relação solos/vegetação em área natural no parque estadual de Porto Ferreira, São Paulo. Revista do Instituto Florestal, v.17, n.1, p.45-61, 2005.

ROPPA, C. Avaliação da dinâmica da restauração de ecossistemas perturbados da mata atlântica em uma região de exíguos atributos ambientais, Nova Iguaçu - RJ. 2009. 140f. Dissertação (Mestrado em Ciências Ambientais e Florestais) - Universidade Federal Rural do Rio de Janeiro, Seropédica, 2009.
TOLEDO, L. O.; PEREIRA, M. G. Dinâmica da deposição de serrapilheira em florestas secundárias do município de Pinheiral, RJ.

Floresta e Ambiente, v.11, n.1, p.39-46, 2004.

TRÊS, D. R. et al. Banco de sementes como indicadores para a restauração ecológica de matas ciliares. Revista Brasileira de Biociências, v.5, n.1, p.309-311, 2007.

UHL, C. Factores controling succession following slash and burn agriculture in Amazonian. Jornal of Ecology, v.75, n.2, p.377-407, 1987.

VALCARCEL, R.; SILVA, Z. S. Eficiência conservacionista de medidas de recuperação de áreas degradadas: proposta metodológica. Floresta e Ambiente, v.27, n.1/2, p.101-114, 1997.

ZAR, J. H. Biostatistical analysis. 4.ed. New Jersey: Prentice-Hall, 1999. 663p.

ZAÚ, A. S. Cobertura vegetal:

transformações e resultantes

microclimáticas e hidrológicas

superficiais na vertente norte do morro do Sumaré, Parque Nacional da Tijuca, RJ. 1994. 179f. Dissertação (Mestrado em Geografia) - Universidade Federal do Rio de Janeiro, Rio de Janeiro, 1994.

WEVER, J. E.; CLEMENTS, F. E. Plant ecology. 2.ed. New York: Tata Mcgraw-Hill, 1980. 601p. 